\title{
Environmentally-friendly concretes for sustainable building
}

\author{
V. Corinaldesi \& G. Moriconi \\ Department SIMAU, Università Politecnica delle Marche, Ancona, Italy
}

\begin{abstract}
The concept of sustainable development includes the judicious use of natural resources, which in some areas are rapidly depleting, achieved by using industrial by-products and thereby reducing materials waste. In addition, it is necessary to reduce energy consumption that is associated with $\mathrm{CO}_{2}$ and other greenhouse gas emissions. The production of Portland cement also releases large amounts of $\mathrm{CO}_{2}$ into the atmosphere. For this reason supplementary cementitious materials are being used in concrete: one of these materials is fly ash, which is a by-product of thermal power generation. Fly ash exhibits pozzolanic activity, and, if not used, has to be disposed of in landfills at a considerable cost. The use of other non-renewable resources, such as virgin aggregates, also needs to be reduced by recycling rubble from demolished buildings, processed in such a way that they can be used to replace virgin fine and coarse aggregate in concrete. This replacement also allows for reduction in the volume of materials disposed of in landfills. According to the concept of sustainable development, the environmental load of a building must be evaluated throughout its life cycle, from design to construction, maintenance or repair, demolition, and rubble disposal. Therefore, from a holistic point of view, sustainable construction means designing a reinforced concrete structure with appropriate durability during a specified service life. This paper discusses the effect of partial and full replacement of natural aggregates by recycled concrete aggregates (RCA) in a fly ash concrete. Engineering properties and durability performance have been examined for mixtures designed with various proportions of the RCA by mass. Results obtained showed that while incorporating high RCA amount could lower concrete performance, the combined use of RCA and fly ash could allow us to achieve adequate engineering properties and durability.

Keywords: durability, fly ash, recycled concrete aggregate, recycling, recycled aggregate concrete, sustainable building.
\end{abstract}




\section{Introduction}

The concept of "Sustainability" was introduced with the "Brundtland Report" in 1987 by the World Commission on Environment and Development, and it was defined as "development and promotion of economic activities which are in harmony with the earth's ecosystem" [1]. It represents the possibility of meeting the present needs without preventing future generations from meeting their needs. In other words, problems that arise due to present human actions should not to be passed on to future generations. The same concept has been expressed also in the Kyoto protocol (1997), an international environmental treaty with the goal of achieving the "stabilization of greenhouse gas concentrations in the atmosphere at a level that would prevent dangerous anthropogenic interference with the climate system" [2].

Sustainable development means, among other things, a judicious use of natural resources, which are rapidly depleting. Such depletion can be, and should be, reduced by using industrial by-products and thereby reducing waste. Secondly, it is necessary to reduce energy consumption that is associated with carbon dioxide $\left(\mathrm{CO}_{2}\right)$ and other green-house gases (GHG) emissions, which are the primary cause for the well-known "greenhouse effect". The production of Portland cement also releases $\mathrm{CO}_{2}$ and other GHG into the atmosphere. As an alternative for cement, supplementary cementing materials (SCM) should be used in concrete as a partial cement replacement [3]. Use of SCM would help achieve sustainable development. One of these materials is fly ash (FA), which is a by-product of coal-combustion at thermal power generation. FA possesses pozzolanic ability, and, if not used, has to be disposed of in landfills at a considerable cost. The use of other non-renewable resources, such as virgin aggregates, also needs to be reduced. This can be achieved by recycling concrete-rubble from demolished construction. Rubble can be processed in such a way that they can be used as recycled concrete aggregate (RCA) to replace virgin inert in mortars [4-5] and concretes [6-14], by reducing both natural resource consumption and volume of materials disposed of in landfills.

According to the concept of sustainable development, the environmental load of a building must be evaluated throughout its life cycle, i.e. from design to construction, maintenance, repair, demolition, and rubble disposal. Therefore, from a holistic point of view, sustainable construction means designing a concrete structure with appropriate durability during a specified service life. Over-designed structures should be avoided because they represent energy and resource waste; on the other hand, under-designed structures can cause excessive repair cost and environmental loads. To reduce the maintenance cost of reinforced concrete structures, the concrete cracking and the ingress of aggressive ions through concrete open porosity should be counteracted, in particular for reducing the risk of steel reinforcement corrosion. This can be achieved, for instance, by judiciously selecting the concrete mixture proportions.

This paper discusses the effect of partial replacement of virgin aggregates by RCA in a fly ash concrete, as well as in concrete prepared with another kind of industrial by-product, that is marble powder. 


\section{Experimental part}

Engineering properties and durability performance have been examined for mixtures designed with various proportions (either $10 \%$, or $20 \%$, or $30 \%$ ) of the RCA by mass.

\subsection{Materials}

A commercial Portland-limestone blended cement type CEM II/A-L 42.5 R according to EN-197/1 was used.

A low-calcium fly ash (ASTM C 618 Class F) produced by a thermal generating station was used. The Blaine fineness of fly ash was $480 \mathrm{~m}^{2} / \mathrm{kg}$ and its relative density (specific gravity) was 2.25 .

As a filler, instead of fly ash, marble powder (MP) was used, obtained as a by-product of marble processing. Marble has been commonly used as a building material since ancient times. Waste disposal of the marble industry, consisting of very fine powder, is one of the environmental problems worldwide today. In a previous work [15], this marble powder was characterized from a physical and chemical point of view by proving its suitability for use in mortar and concrete production. Its relative density was 2.55 and the value of Blaine fineness was $1500 \mathrm{~m}^{2} / \mathrm{kg}$.

Quartz sand $(0-5 \mathrm{~mm})$, fine gravel $(6-12 \mathrm{~mm})$ and gravel $(11-22 \mathrm{~mm})$ were used, suitably combined, for preparing the reference mixtures. Then a recycled aggregate fraction $(6-15 \mathrm{~mm})$ was used, replacing fine gravel, coming from a recycling plant in which rubble from concrete structure demolition are selected (after a proper quality check, in order to avoid hazardous materials such as asbestos or chalk), then ground, cleaned and sieved. Their composition is $100 \%$ recycled concrete; the original concrete strength class was unknown and likely different for waste concrete coming from different sources.

The main physical properties of the aggregate fractions, evaluated according to EN 1097-6, are reported in Table 1 and their gradations, evaluated according to EN 933-1, are shown in Figure 1. In addition, reported data concerning the pore structure of the aggregate fractions and the mean value of their total open porosity are reported in Table 1 . These results were obtained by means of mercury intrusion technique as the mean value calculated on five samples for each aggregate fraction. The content in the recycled concrete fraction of chlorides, sulphates, organic materials were evaluated according to the methods recommended by UNI EN 1744-1 (part 7, 11, 12, 14 and 15) and the presence of alkali-silica reactive materials according to the method recommended by UNI EN 8520-22. No organic or alkali-silica reactive materials were detected; concerning the amount of chlorides and sulphates they were below $0.04 \%$ (by weight) and $0.15 \%$ (by weight) respectively.

As water reducing admixture, a $30 \%$ aqueous solution of carboxylic acrylic ester polymer was added to the mixtures. 
Table 1: $\quad$ Main physical and microstructural properties of the aggregate used.

\begin{tabular}{|c|c|c|c|c|}
\hline Aggregate Fractions & $\begin{array}{c}\text { Quartz } \\
\text { sand }\end{array}$ & Fine gravel & Gravel & $\begin{array}{c}\text { Recycled } \\
\text { fraction }\end{array}$ \\
\hline Relative Specific Gravity (SSD) & 2.60 & 2.62 & 2.63 & 2.30 \\
\hline Water Absorption, \% & 3.5 & 3.0 & 3.0 & 8.8 \\
\hline Total open porosity, \% & 11.5 & 11.9 & 9.7 & 17.8 \\
\hline Mean pore size, nm & 112 & 124 & 120 & 146 \\
\hline
\end{tabular}

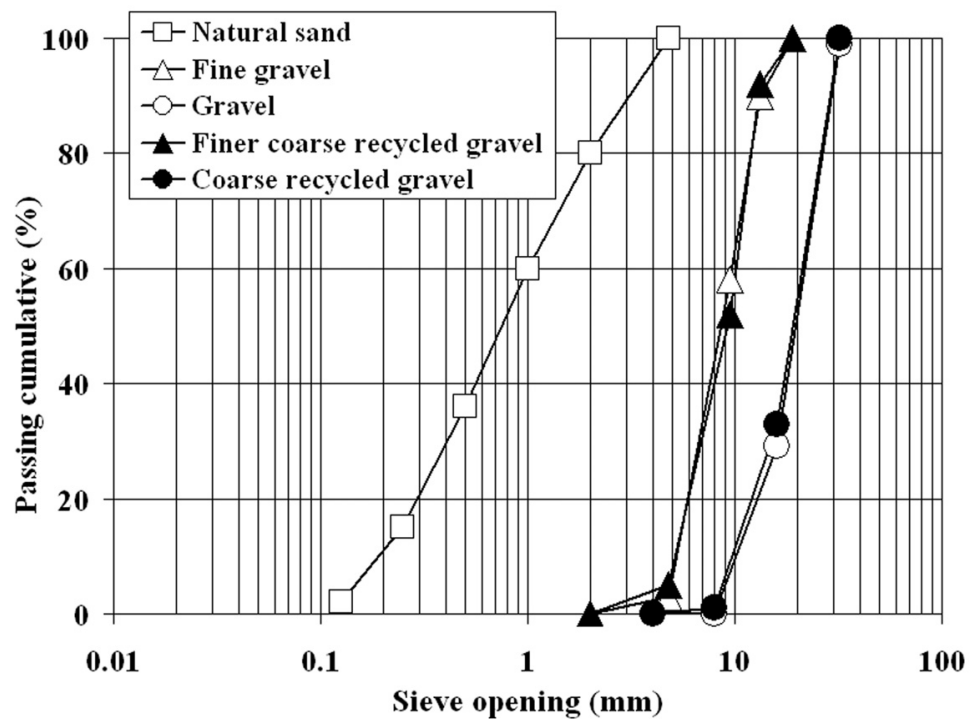

Figure 1: Grain size distribution curve of the aggregate fractions.

\subsection{Mixture proportions}

The concrete mixture proportions of the reference mixture (Ref) made of $100 \%$ virgin aggregates, of the mixtures made of recycled aggregate replacing fine gravel at different percentages by volume of the overall aggregate, $10 \%, 20 \%$ and $30 \%$ (Rec- $10 \%$, Rec- $20 \%$, Rec-30\%), and of the mixtures made of either fly ash (FA) or marble powder (MP), used in the reference mixtures as well as in those prepared with 30\% recycled aggregate (Ref $+\mathrm{FA}$, Ref $+\mathrm{MP}$, Rec-30\%+FA, Rec-30\%+MP) are reported in Table 2.

The recycled-aggregate fraction was added to the mixture after water-soaking, in a condition very close to that defined as saturated surface-dried.

The same water to cement ratio of 0.50 was adopted for all the mixtures, which showed also the same fluidity level (16-18 cm slump), according to EN 12350-2. 
Table 2: $\quad$ Mixture proportions of concretes.

\begin{tabular}{|c|c|c|c|c|c|c|c|c|}
\hline Mixture & Ref & $\begin{array}{c}\text { Ref } \\
+\mathrm{FA}\end{array}$ & $\begin{array}{c}\text { Ref } \\
+\mathrm{MP}\end{array}$ & $\begin{array}{c}\text { Rec- } \\
10 \%\end{array}$ & $\begin{array}{c}\text { Rec- } \\
20 \%\end{array}$ & $\begin{array}{c}\text { Rec- } \\
30 \%\end{array}$ & $\begin{array}{c}\text { Rec- } \\
30 \%+\mathrm{FA}\end{array}$ & $\begin{array}{c}\text { Rec- } \\
30 \%+\mathrm{MP}\end{array}$ \\
\hline Water/Cement & 0.50 & 0.50 & 0.50 & 0.50 & 0.50 & 0.50 & 0.50 & 0.50 \\
\hline Water/Binder & 0.50 & 0.42 & 0.50 & 0.50 & 0.50 & 0.50 & 0.42 & 0.50 \\
\hline Water, kg & 165 & 165 & 165 & 165 & 165 & 165 & 165 & 165 \\
\hline Cement, kg & 330 & 330 & 330 & 330 & 330 & 330 & 330 & 330 \\
\hline FA, kg & - & 66 & - & - & - & - & 66 & - \\
\hline MP, kg & - & - & 81 & - & - & - & - & 81 \\
\hline Sand, kg & 740 & 665 & 665 & 740 & 740 & 740 & 665 & 665 \\
\hline Fine gravel, kg & 560 & 560 & 560 & 340 & 187 & - & - & - \\
\hline Gravel, kg & 560 & 560 & 560 & 560 & 560 & 560 & 560 & 560 \\
\hline RAC, kg & - & - & - & 165 & 330 & 490 & 490 & 490 \\
\hline Superplasticizer, kg & 2.6 & 3.2 & 3.2 & 2.6 & 2.6 & 2.6 & 3.2 & 3.2 \\
\hline
\end{tabular}

In order to optimize the grain size distribution of the solid particles in the concrete, the aggregate fractions were suitably combined at percentages of $40 \%$, $30 \%$ and $30 \%$ of sand, fine gravel and gravel, respectively.

A water reducing admixture was always added to the mixtures at a dosage of $0.6 \%$ by weight of very fine materials (cement + fly ash + marble powder).

\subsection{Preparation, curing and testing of specimens}

Thirty-three cubic specimens, $100 \mathrm{~mm}$ in size, were cast in steel forms according to UNI EN 12390-1 (and wet cured at $20^{\circ} \mathrm{C}$ ) for each concrete mixture: twelve of them for compression tests, five for splitting tension tests, eight for the evaluation of carbonation depth, as well as further eight for the chloride penetration depth.

Compression tests were carried out after 1, 7, 28 and 56 days according to EN 12390-3), by testing three specimens for each curing time and each mixture at right angles to the position of casting.

Splitting tension tests were carried out after 28 days on five specimens for each concrete mixture according to EN 12390-6.

The carbonation depth was measured by the phenolphthalein test, according to EN 14630, on eight cubic specimens for each concrete mixtures, after 1, 2, 3 and 4 months of exposure to open air at a temperature of $20^{\circ} \mathrm{C}$.

The chloride penetration into concrete was evaluated through the silver nitrate and fluorescein test (EN 14629). Both solutions were sprayed on the two fractured surfaces obtained by splitting two cubic specimens for each concrete mixtures and each time of testing (1,2, 3 and 4 months of exposure to a $10 \%$ sodium chloride aqueous solution at a temperature of $\left.20^{\circ} \mathrm{C}\right)$.

In addition, three prismatic specimens $(100 \times 100 \times 500 \mathrm{~mm})$ were prepared for each concrete mixture in order to carry out 3-point bending tests, according to EN 12390-5 specifications, after 28 days of curing. 
Finally, for free drying shrinkage monitoring, further three prismatic specimens $(100 \times 100 \times 500 \mathrm{~mm})$ were prepared for each concrete mixture according to UNI 11307. After one day of wet curing, the specimens were stored at constant temperature $\left(20 \pm 2^{\circ} \mathrm{C}\right)$ and constant relative humidity $(50 \pm 2 \%)$, while measuring drying shrinkage at different curing times up to 60 days of exposure.

\section{Results and discussion}

\subsection{Compression tests}

Figure 2 shows the compressive strength as a function of time for the eight concretes prepared. A positive effect of fly ash on compressive strength is quite evident $(+25 \%)$, particularly at longer ages, while the effect of the recycled aggregate addition does not seem to significantly affect compressive strength, with a maximum strength loss of $8 \%$ in the presence of $30 \%$ recycled aggregate (completely replacing fine gravel).

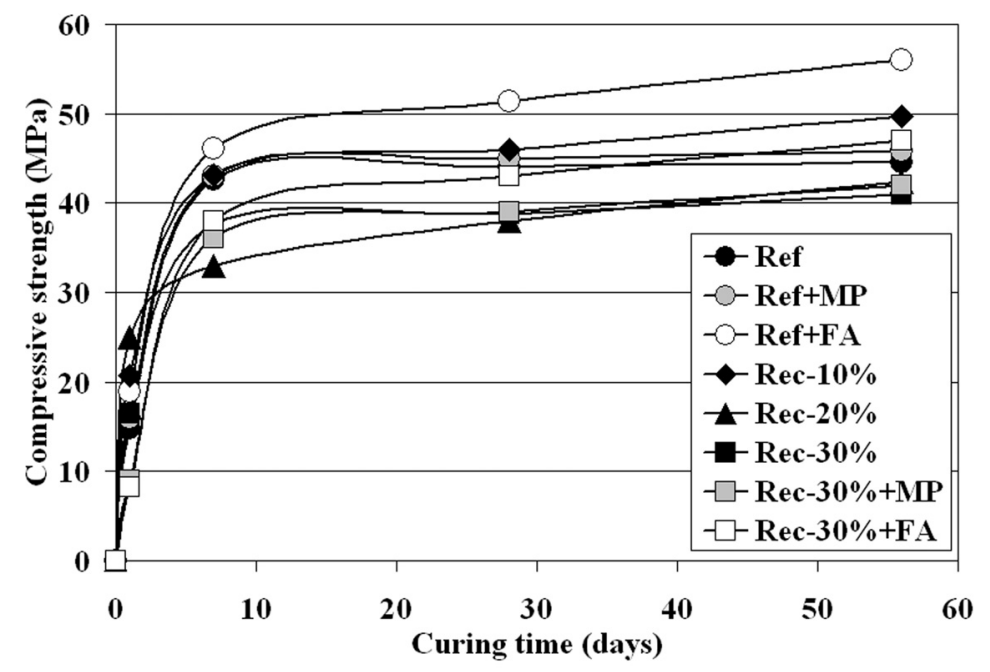

Figure 2: Compressive strengths vs. curing time.

\subsection{Splitting tensile and 3-point bending tests}

Figure 3 shows the results obtained after 28 days of curing by means of splitting tension tests and 3-point bending tests. The effect of the recycled aggregate addition again does not seem to significantly affect flexural strength, with a maximum strength loss of $6 \%$ in the presence of $30 \%$ recycled aggregate (completely replacing fine gravel). In terms of tensile strength even higher values were detected when the recycled aggregate was used instead of fine gravel, whichever its dosage. On the other hand the use of marble powder seems to 
compromise concrete performance either under tension $(-25 \%)$ or bending $(-21 \%)$, due to its high surface area (three times that of fly ash, see $\S 2.1)$, which caused a remarkable water absorption, so to increase the real water to cement ratio.

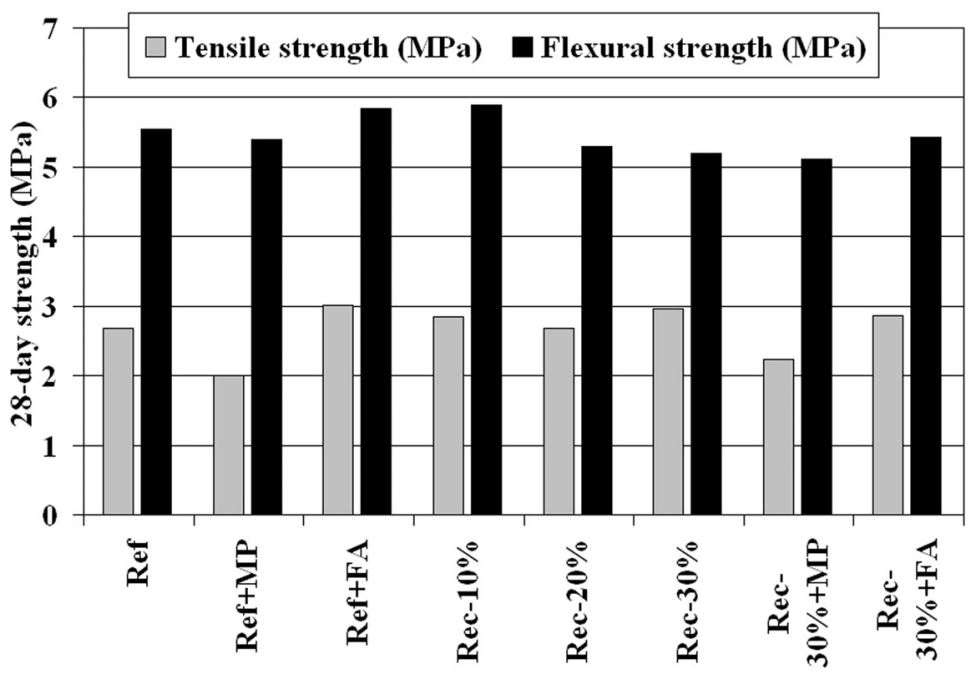

Figure 3: Tensile and flexural strengths after 28 days of curing.

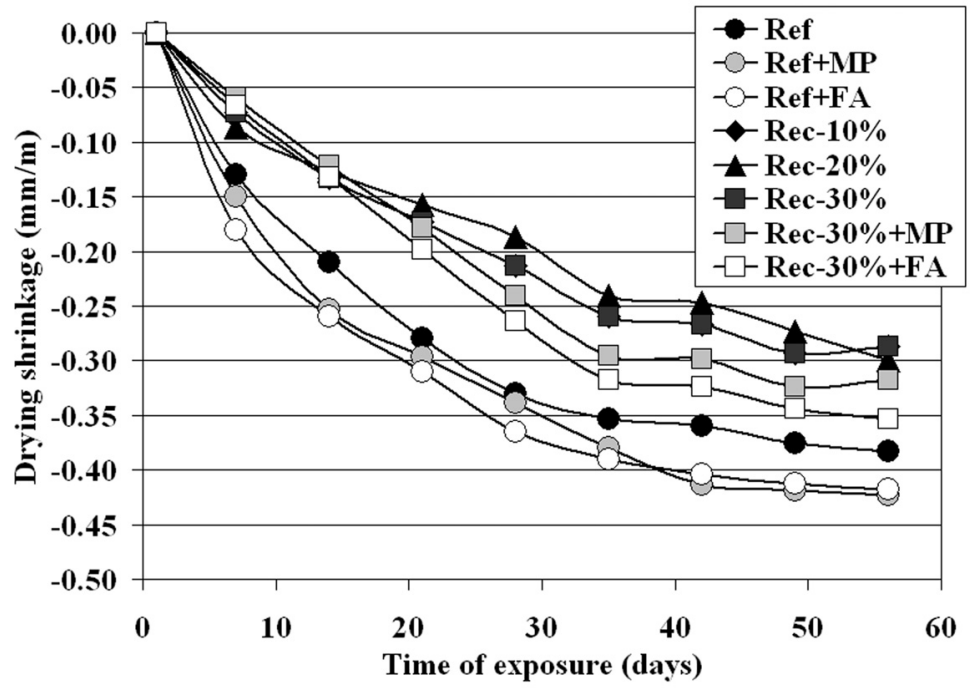

Figure 4: $\quad$ Drying shrinkage vs. time of exposure. 


\subsection{Drying shrinkage measurements}

Figure 4 shows the drying shrinkage measurements as a function of time of exposure. The use of porous aggregates such as the recycled concrete aggregate, suitably water pre-soaked, allows us to create an internal water supply able to reduce drying-shrinkage. This is the so-called 'internal curing effect', already detected by the authors in previous experimental works $[8,9]$.

\subsection{Carbonation and chloride penetration depths}

Figure 5 shows the carbonation depth (in $\mathrm{mm}$ ) as a function of square root of the time of exposure to air (in days). Carbonation depth varies with elapsed time following Eq. (1):

$$
\mathrm{X}=\mathrm{K} \cdot \sqrt{\mathrm{t}}
$$

where $x=$ carbonation depth, $t=$ elapsed time and $K=$ constant value, expressed in $\mathrm{mm} / \mathrm{s}^{1 / 2}$. The values of $K$ were obtained from Eq. (1), by interpolating the results shown in Fig. 5 for the various concretes. Results are reported in Table 3.

Table 3: Coefficients for carbonation rate and chloride diffusivity.

\begin{tabular}{|c|c|c|c|c|c|c|}
\hline Mixture & Ref & Ref+FA & Rec-10\% & Rec-20\% & Rec-30\% & Rec-30\%+FA \\
\hline $\mathrm{K}\left(\mathrm{mm} /\right.$ days $\left.^{1 / 2}\right)$ & 0.143 & 0.122 & 0.124 & 0.093 & 0.164 & 0.102 \\
\hline $\mathrm{D}\left(\mathrm{mm}^{2} \cdot \mathrm{s}^{-1} \cdot 10^{-8}\right)$ & 0.295 & 0.215 & 0.193 & 0.240 & 0.223 & 0.193 \\
\hline
\end{tabular}

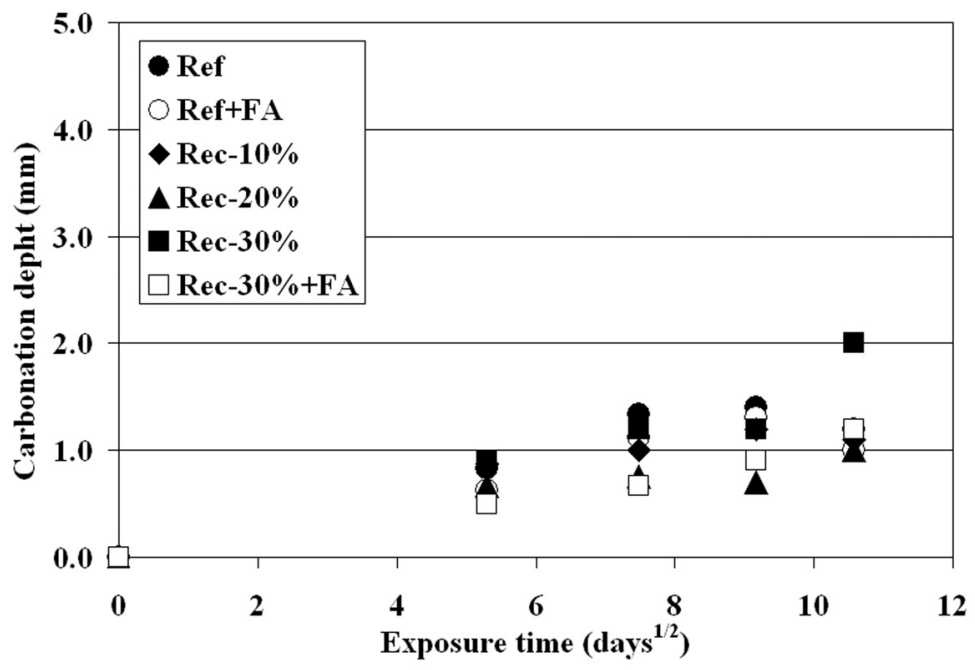

Figure 5: Carbonation depth as a function of the time of exposure to air. 
Figure 6 shows the chloride penetration depth as a function of time of exposure to $10 \%$ sodium chloride aqueous solution after water saturation of concrete specimens. Collepardi et al. [16] found that chloride penetration depth varies with elapsed time following Eq. (2), obtainable from the solution of Fick's second law under non-steady-state conditions for diffusion in a semi-finite solid:

$$
\mathrm{d}=4 \cdot \sqrt{\mathrm{D} \cdot \mathrm{t}}
$$

where $d=$ chloride penetration depth, $t=$ elapsed time and $D=$ diffusion coefficient of chloride ions into concrete pores filled of water, expressed in $\mathrm{mm}^{2}$ $\cdot \mathrm{s}^{-1} \cdot 10^{-8}$. The values of $D$ were obtained from Eq. (2), by interpolating the results shown in Fig. 6 for the different concretes. Results obtained are reported in Table 3.

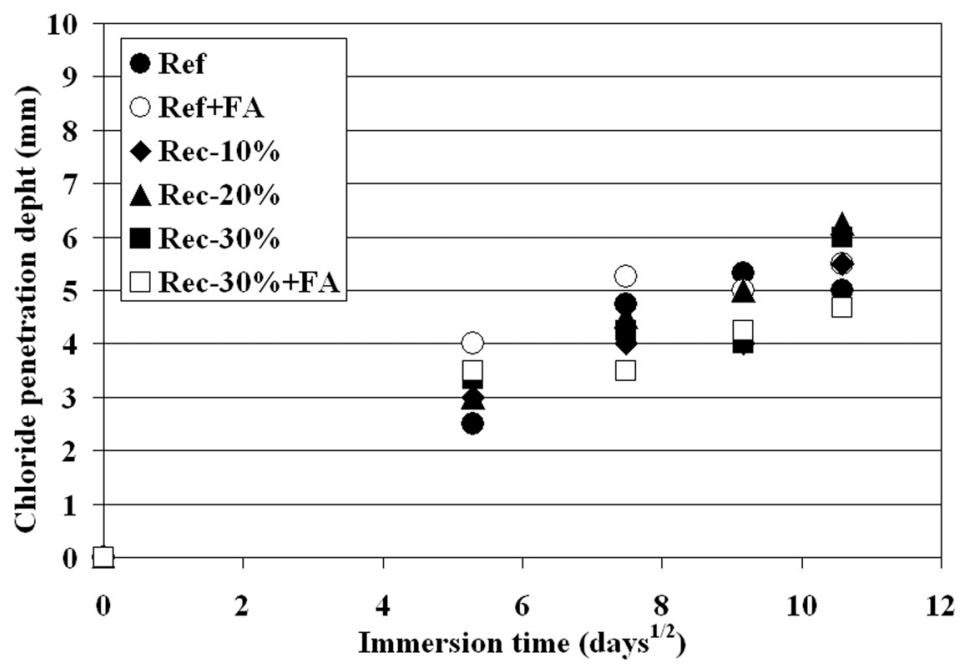

Figure 6: Chloride penetration vs. time of exposure to $10 \% \mathrm{NaCl}$ solution.

On the basis of data reported in Table 3, it can be noticed that the use of both FA and recycled aggregate improves durability of concrete by lowering the penetration depths of both $\mathrm{CO}_{2}$ and chloride ions, with the best result achieved by the mixture prepared with their contemporary use. The reason probably lies in the better quality of the interfacial transition zone between cement paste and aggregate particles due to the pozzolanic effect of fly ash as well as to the internal curing effect due to the porous pre-soaked recycled aggregate particles. This improvement was already checked by the authors in previous works $[6,8,9]$.

\section{Conclusions}

Based on the results of this experimental investigation, it can be concluded that the use of a supplementary cementitious material, such as fly ash, as well as of 
an aggregate fraction coming from recycling process allow to achieve the same, if not better, mechanical performance of ordinary concrete, besides to better durability in terms of lower drying shrinkage (and consequently, lower vulnerability to concrete cracking), as well as lower penetration depth of aggressive ions.

In conclusion, if such industrial by-products are used for preparing environmentally-friendly concretes, also benefits in terms of concrete durability could be achieved, so to promote sustainable building.

\section{References}

[1] Mehta, P.K., Bringing the Concrete Industry into a New Era of Sustainable Development. Proc. Mario Collepardi Symposium on 'Advances in Concrete Science and Technology', ed. P.K. Mehta, ACI: Farmington Hills, pp. 49-67, 1997.

[2] Kyoto protocol, The United Nations Framework Convention on Climate Change, 1997.

[3] Malhotra, V.M., Bilodeau, A., High-Volume Fly Ash System: the Concrete Solution for Sustainable Development. Proceedings Int. Symp. on 'Concrete Technology for Sustainable Development in the Twenty-First Century', ed. P.K. Mehta, Radha Press: New Delhi, pp. 43-64, 1999.

[4] Corinaldesi, V., Moriconi, G., Behaviour of cementitious mortars containing different kinds of recycled aggregate. Construction and Building Materials, 23(1), pp. 289-294, 2009.

[5] Corinaldesi, V., Mechanical behaviour of masonry assemblages manufactured with recycled-aggregate mortars. Cement and Concrete Composites 31(7), pp. 505-510, 2009.

[6] Corinaldesi V. \& Moriconi, G. Behavior of Beam-Column Joints Made of Sustainable Concrete under Cyclic Loading. Journal of Materials in Civil Engineering. 18(5), pp. 650-658, 2006.

[7] Corinaldesi, V., Moriconi, G., Influence of mineral additions on the performance of $100 \%$ recycled aggregate concrete. Construction and Building Materials 23(8), pp. 2723-2972, 2009.

[8] Corinaldesi, V., Mechanical and elastic behaviour of concretes made of recycled-concrete coarse aggregates. Construction and Building Materials 24(9), pp. 1616-1620, 2010.

[9] Corinaldesi, V. Moriconi, G., Recycling of rubble from building demolition for low-shrinkage concretes. Waste Management 30(4), pp. 655-659, 2010.

[10] Kou, S., Poon, C., Exteberria, M., Influence of recycled aggregates on long term mechanical properties and pore size distribution of concrete. Cement and Concrete Composites 33(2), pp. 286-291, 2011.

[11] Soutsos, M.N., Tang, K., Millard, S.G., Concrete building blocks made with recycled demolition aggregate. Construction and Building Materials 25(2), pp. 726-735, 2011. 
[12] Yang, J., Du, Q., Bao, Y., Concrete with recycled concrete aggregate and crushed clay bricks. Construction and Building Materials 25(4), pp. 19351945, 2011.

[13] Corinaldesi, V., Moriconi, G., The role of industrial by-products in selfcompacting concrete. Construction and Building Materials 25(8), pp. 31813186, 2011.

[14] Kou, S., Poon, C., Agrela, F., Comparisons of natural and recycled aggregate concretes prepared with the addition of different mineral admixtures. Cement and Concrete Composites 33(8), pp. 788-795, 2011.

[15] Corinaldesi, V., Moriconi, G., Naik, T.R., Characterization of marble powder for its use in mortar and concrete. Construction and Building Materials 24(1), pp. 113-117, 2010.

[16] Collepardi, M., Marcialis, A., Turriziani, R., Penetration of Chloride Ions into Cement Pastes and Concretes. Journal of American Ceramic Society 53, pp. 534-535, 2972. 